\section{CASE OF OLD-STANDING DISLOCATION OF HIP-JOINT TREATED BY OPEN OPERATION.}

By A. GIBSON, M.A., M.B., CH.B. EdrN.,

MEDICAL SUPERINTENDENT AND SURGIOAL REGISTRAR, SEAMEN'S HOSPITAL SOCIETY (DREADNOTGHT), GREENWICH.

THE patient, a Chinaman, aged 49 , was admitted to the Seamen's Hospital, Greenwich, under the care of $\mathrm{Mr}$. E. Rock Carling, on May 1st, 1912. His history was that some eight weeks previously he had been struck on the outer side of the right hip by a lifeboat which was being lowered. The ship was at the time in the Indian Ocean, and the condition remained untreated until his arrival in London on May 1st.

On admission the right lower limb was flexed and rotated inwards at the hip-joint. The knee-joint was flexed. The great trochanter was unduly prominent, and behind the great trochanter the head of the femur was palpable. There was considerable atrophy of both flexors and extensors of the thigh. There was no evident bunching up of the external rotators of the thigh. The diagnosis of median dorsal dislocation was made and confirmed by the $\mathrm{X}$ rays.

On May 3rd a general anæsthetic was administered and a strenuons attempt made to replace the head of the femur. This proved futile. The patient was put back to bed and $12 \mathrm{lb}$. extension was applied in the line of the femur. On the 10th an open operation was performed. As a result of the extension the limb was distinctly more mobile. The incision resembled somewhat that for a Kocher posterior hipresection. Commencing below the base of the great trochanter, it ran up as if making for the anterior superior spine of the ilium, as far as the summit of the great trochanter. From here it was carried backwards towards a point about 3 inches behind the anterior superior iliac spine. The fascia covering the gluteus medius was divided in the same line as the upper portion of the incision. The gluteus maximus was partially divided in a direction transverse to that of its fibres. The outer surface of the great trochanter being exposed, the vastus externus was eut through close to its origin. The obturator externus tenclon was next cut through close to its insertion. It was seen that the head of the femur had passed below this tendon. The great trochanter with its attached muscles was then severed from the femur by an oblique saw-cut made in the plane of the upper surface of the neck of the femur. By this means free access was obtained to the acetabular region. The head of the femur was displaced right out of the wound. The acetabular cavity was well-nigh obliterated, the capsule being doubled into it and having become adherent, so that the aperture now admitted with diffeulty a finger-tip. The adherent capsule was removed with gouge and with scissors until the cavity was clear. The head of the bone was then with considerable difficulty replaced in the acetabulum. This was done by leverage combined with manipulation. A fulcrum was obtained at the junction of the shaft and neck by resting the bone at this point upon a vertically placed steel rod (periosteal elevator) the lower end of which rested on the firm table. In spite of the fact of free muscular detachment considerable force was necessary The severed muscles were then sutured; the great trochanter was replaced and fixed in position by two screws. The wound was closed with silkworm-gut sutures. As soon as the patient was put back to bed extension of $8 \mathrm{lb}$. weight was applied. A long Liston splint was secured to the left (sound) side.

On June 1st the splints were removed and massage was commenced. 'Ten days later on testing, it was found that movement at the hip-joint was almost nil. The knee-joint and hip-joint were submitted to very thorough passive movement. By June 25th, massage being continued, movement at the hip-joint was distinctly more free, and the patient was encouraged to move the limb himself. On July 1st he was allowed out of bed. It was then observed that he had considerable foot-drop on the right side. During the month of Ju'y he went about with crutches. Towards the end of the month the crutches were removed and two stout walking. sticks substituted for them. Not, however, until the latter part of August did he go about without the aid of the sticks. The drop-foot condition showed distinct improvement.
On Sept. 16th the patient dispensed entirely with the sticks. A boot with a toe-raising spring was procured for him. On Oct 2nd he was discharged from hospital. Very slight movement was taking place at the hip-joint, and he "dipped" the pelvis a little at each step. The functional result, however, was very good, and the patient departed with the intention of resuming work as a ship's fireman.

Several points of interest emerge from the study of this case. 1. The futility of expecting reduction by manipulation after so long a period as eight weeks. 2. The use of a lever in replacing the head of the bone. 3. The excellent exposure given by the posterior incision. 4. The great sciatic nerve was not seen during the operation.

I am indebted to Mr. Rock Carling for permission to publish this case.

Greenwich.

\section{THE TREATMENT OF RECENT INJURY BY MOBILISATION AND MASSAGE.}

By JAMES B. MENNELL, M.A., M.D., B.C. CANTAB., \&C.

THE pioneer in the treatment of fractures by mobilisalion and massage was Lucas-Championnière; he has been followed by disciples who have developed his method and applied it to other forms of recent injury, accidental and post-operative-to almost every class of case, in fact, in which massage forms an integral part of treatment. The massage used consists of a slow, light, rhythmical stroking in the neighbourhood of the injury, the movement being: merely a "caress" and "almost resembling a mesmeric pass," while the actual site of injury is scrupulously avoided. The mobilisation must be regarded in the light of a therapentic measure, the dose being meted out with care and accuracy. It consists of two elements - passive movement and actire movement. When the dose of passive movement is being given the patient must be made to coöperate by actirely relaxing the whole part. Failure to obtain this active relaxation, or the application of any other form of massage to the injured part, is contrary to Lucas-Championnière 's teaching, and absence of a satisfactory result in such circumstances must be ascribed to the practitioner and not to the treatment.

The axiom underlying the whole of the treatment is that " movement is life," and although the massage undoubtedly has a profound effect in the restoration of the injured part to health and strength, yet it may be said, broadly speaking, to be no more than the means of which mobilisation is the end. All the generally accepted forms of massage aim at compulsion, whether of the blood in a given direction or of some movement. The massage now advocated, on the contrary, only attempts, by its reflex action through the nervous system, to restore the tone of the vaso-motor system which has been disorganised by the shock of injury; and in like manner to combat the injury sustained by the nerves in connexion with the injured part.

An indication of the reflex action of the massage is the disappearance of the pain and spasm after fracture, and the beneficial effect of treatment is to be seen in the results obtained after such injury. Thus a severe Colles's fracture has been restored to perfect movement, though not to perfect strength, 10 days after fracture; a ballet-girl has been known to take part in rehearsals three weeks after fracture of the surgical neck of the humerus; a goods porter to be at work six weeks after sustaining fracture through the middle of the shaft of the bone; and a costermonger to push his barrow about Lambeth four weeks after he had sustained a Pott's fracture with severe outward dislocation of the foot. By this method a fortnight should suffice for the restoration of a patient who has dislocated his shoulder. A patient who had his internal semilunar cartilage removed 18 months ago, and who has had no trace of subsequent trouble, was able to walk up and down a long flight of stairs and go for a motor drive ten days after operation. As a cure for insomnia the stroking massage is unrivalled, while as a cure for neurasthenia its success, when other forms of massage have failed, is most striking. In these cases the action of the massage is not, as has been

1 Fpitome of a paper read bafcre the Medical Society of London on Jan. Lith. 